\title{
Patterns and Trends of Cancer Screening in Canada: Results From a Contemporary National Survey
}

\author{
Omar Abdel-Rahman, MD
}

\begin{abstract}
Background: The aim of this study was to assess the patterns and trends of colorectal, breast, and cervical cancer screening within a contemporary cohort of Canadian adults. Methods: Canadian Community Health Survey datasets (2007-2016) were accessed and 3 cohorts were defined: (1) a colorectal cancer (CRC) screening cohort, defined as men and women aged 50 to 74 years with complete information about CRC screening tests and their timing; (2) a breast cancer screening cohort, defined as women aged 40 to 74 years with complete information about mammography and its timing; and (3) a cervical cancer screening cohort, defined as women aged 25 to 69 years with complete information about the Papanicolaou (Pap) test and its timing. Multivariable logistic regression analysis was then performed to evaluate factors associated with not having timely screening tests at the time of survey completion. Results: A total of 99,820 participants were considered eligible for the CRC screening cohort, 59,724 for the breast cancer screening cohort, and 46,767 for the cervical cancer screening cohort. Among eligible participants, $43 \%$ did not have timely recommended screening tests for CRC, $35 \%$ did not have timely mammography (this number decreased to $26 \%$ when limiting the eligible group to ages $50-74$ years), and $25 \%$ did not have a timely Pap test. Lower income was associated with not having a timely recommended screening tests for all 3 cohorts (odds ratios [95\% Cl]: 1.86 [1.76-1.97], 1.89 [1.76-2.04], and 1.96 [1.79-2.14], respectively). Likewise, persons self-identifying as a visible minority were less likely to have timely recommended screening tests in all 3 cohorts (odds ratios for White race vs visible minority [95\% $\mathrm{Cl}]$ : 0.87 [0.83-0.92], 0.85 [0.80-0.91], and 0.66 [0.61-0.70], respectively). Conclusions: More than one-third of eligible individuals are missing timely screening tests for CRC. Moreover, at least one-quarter of eligible women are missing their recommended breast and cervical cancer screening tests. More efforts from federal and provincial health authorities are needed to deal with socioeconomic disparities in access to cancer screening.
\end{abstract}

J Natl Compr Canc Netw 2021;19(1):68-76 doi: $10.6004 /$ jnccn.2020.7613

\footnotetext{
${ }^{1}$ Department of Oncology, University of Alberta and Cross Cancer Institute,
} Edmonton, Alberta, Canada.

\section{Background}

Cancer screening programs represent a pivotal component of all cancer care programs among different Canadian jurisdictions. ${ }^{1}$ Previously published evidence has shown that targeted screening for some solid tumors is associated with reduced cancer mortality and significant cost savings for healthcare systems. ${ }^{2-6}$ Routinely collected administrative cancer databases do not provide clear information about uptake and adherence of different screening programs because they focus on individuals with a confirmed cancer diagnosis. Cross-sectional studies may be more relevant to the assessment of adherence to different cancer screening programs. ${ }^{7}$

The Canadian Community Health Survey (CCHS) is a cross-sectional study conducted annually and can provide a better venue for assessing different health behaviors of Canadians, including the use of cancer screening tests. ${ }^{8}$ It can also assess potential disparities in the uptake of recommended cancer screening tests among different populations in Canadian society. This study therefore used the CCHS to evaluate these trends.

Results of the current study are important for policymakers, healthcare providers, and the Canadian public because they can guide future resource allocation and system improvements for different cancer screening programs across the country.

\section{Methods}

\section{About CCHS}

CCHS is a cross-sectional survey that compiles information every 2 years related to health determinants for the Canadian population aged $>12$ years. It is based on sampling of a large population of respondents and is designed to provide reliable estimates at the health region level on a regular basis. To provide these estimates, a total of 130,000 respondents is needed on the 2-year basis: 120,000 respondents to represent the population

\section{See JNCCN.org for supplemental online content.}


aged $\geq 18$ years and 10,000 respondents to represent the population aged 12 to 17 years. $^{9}$

Sampling strategy, data collection, and dataset release are organized by Statistics Canada in coordination with relevant federal, provincial, and territorial authorities. A total of $3 \%$ of the Canadian population is not represented in CCHS surveys, including members of the Canadian armed forces, people living in medical facilities, individuals living on reserves and other indigenous settlements in the provinces, and people in some northern health regions in the province of Quebec. As described in previously published CCHS documentation, ${ }^{10}$ in order to enhance the data from the survey and reduce respondent burden, Statistics Canada combines the information from the CCHS with information provided by respondents (including tax data). Furthermore, Statistics Canada, respondents' respective provincial ministry of health, and the Institut de la Statistique du Québec may combine data provided by respondents with that from other surveys or administrative sources.

The current study is based on CCHS annual cohorts from 2007 to 2016. CCHS data covering this period was released in 5 sequential datasets, each representing 2 consecutive years (2007-2008, 2009-2010, 2011-2012, 2013-2014, and 2015-2016).

\section{Cohort Selection}

The current study contains 3 different cohorts of participants, and selection criteria were based on the recommendations of the Canadian Task Force on Preventive Health Care (CTFPHC). ${ }^{11}$ The colorectal cancer (CRC) screening cohort was defined as men and women aged 50 to 74 years with complete information about whether and when prior fecal occult blood testing (FOBT) and/or sigmoidoscopy or colonoscopy was performed. ${ }^{12}$ Participants were considered adherent to the CTFPHC CRC screening guidelines if they had FOBT performed within the last 2 years or sigmoidoscopy/ colonoscopy performed within the last 10 years.

The breast cancer screening cohort was defined as women aged 40 to 74 years with complete information about mammography use and its timing. Because mammography screening for women aged 40 to 49 years was not formally recommended in the most recent update of the CTFPHC breast cancer screening recommendations (rather, a shared decision-making process between physicians and patients was recommended) and because screening practices for this subgroup vary across different Canadian jurisdictions, a sensitivity analysis was conducted, repeating all analyses on women aged 50 to 74 years with complete information about mammography use and its timing. ${ }^{5}$ Women were considered adherent to the CTFPHC breast cancer screening guidelines if they had mammography performed within the last 2 years.
The cervical cancer screening cohort was defined as women aged 25 to 69 years with complete information on Papanicolaou (Pap) test performance and its timing. ${ }^{13}$ Women were considered adherent to the CTFPHC cervical cancer screening guidelines if they underwent a Pap test within the last 3 years. To avoid the possibility that some participants may have had these tests not as a part of regular screening but rather as part of an investigation, treatment, or follow-up for cancer, a sensitivity analysis was conducted in all 3 cohorts excluding patients who reported any concurrent cancer diagnosis (CCHS datasets did not specify the type of cancer). Unfortunately, CCHS does not provide detailed information about cancer symptoms; thus, those data could not be considered in the sensitivity analyses. Prostate cancer screening was not evaluated in the current study because current CTFPHC guidelines recommend against routine prostate-specific antigen screening for men with an average risk of prostate cancer. ${ }^{14}$

Note that models for cancer screening differ among different Canadian jurisdictions and among different cancers. In some jurisdictions/cancers, screening is coordinated by a centralized registry that is supported by family physicians and other healthcare providers; in other jurisdictions/cancers, screening coordination is conducted completely by healthcare providers.

\section{Data Collection}

The following data were collected (where available) from all included participants in the current study: age at survey completion, sex, racial group (self-identified), marital status, income, self-perceived health, self-perceived mental health, province of residence, and FOBT, colonoscopy/sigmoidoscopy, mammography, or Pap test and timing. Note that information about $\geq 1$ of the 3 evaluated cancer screening interventions were not reported in the CCHS from some Canadian jurisdictions. Supplemental eTable 1 provides a detailed description of the availability of data within CCHS according to jurisdiction (available with this article at JNCCN.org).

\section{Statistical Analysis}

Chi-square testing was initially used to compare baseline characteristics between participants who had screening tests within the recommended timelines versus those who did not have screening tests within the recommended timelines (as detailed in "Cohort Selection"). This testing was repeated, taking into consideration weights provided within successive CCHS datasets (although it was supposed previously that when pooling weights from multiple survey cycles, the resulting weights represent an average population that does not exist). ${ }^{15}$

Multivariable Cox regression analyses was then used to evaluate factors predicting nonadherence to 
Table 1. Factors Associated With Nonadherence to CRC Screening $(\mathbf{N}=\mathbf{9 9 , 8 2 0})$

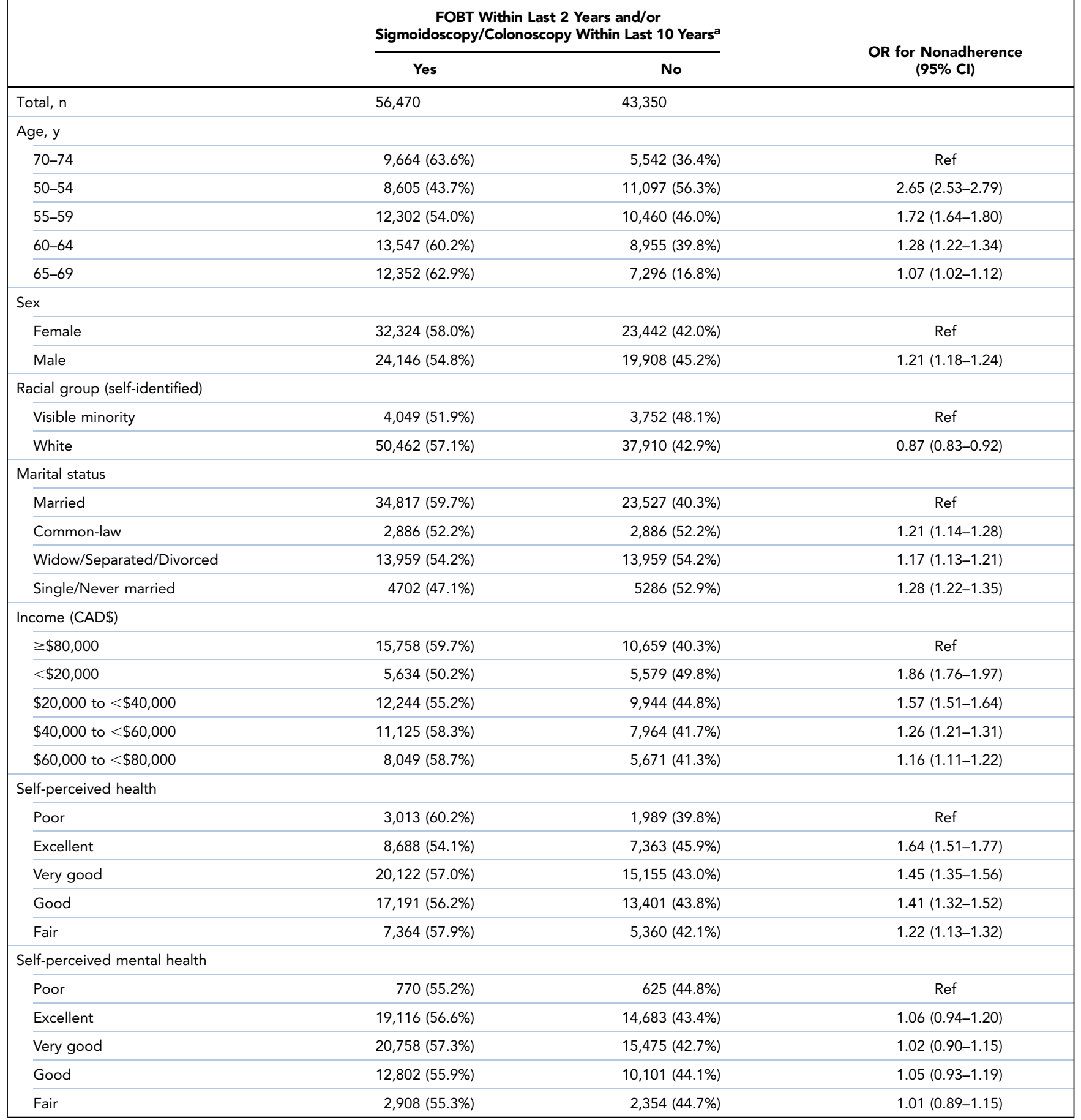

Abbreviations: CRC, colorectal cancer; FOBT, fecal occult blood test; OR, odds ratio.

aMissing data: self-identified racial group $(n=3,647 ; 3.7 \%)$, marital status $(n=220 ; 0.2 \%)$, income $(n=7,193 ; 7.2 \%)$, self-perceived health $(n=174 ; 0.2 \%)$, self-perceived mental health $(n=228 ; 0.2 \%)$.

CTFPHC screening guidelines. Each of these models was adjusted for age, racial group, income, marital status, self-perceived health, and self-perceived mental health. For the CRC screening cohort, the model was also adjusted for sex. All analyses were conducted using SPSS Statistics, version 26 (IBM Corp). Weighted frequencies were conducted through survey analysis section within STATA software, version 14 (STATA corp). 


\section{Table 2. Factors Associated With Nonadherence to Timely Mammography ( $N=59,724)$}

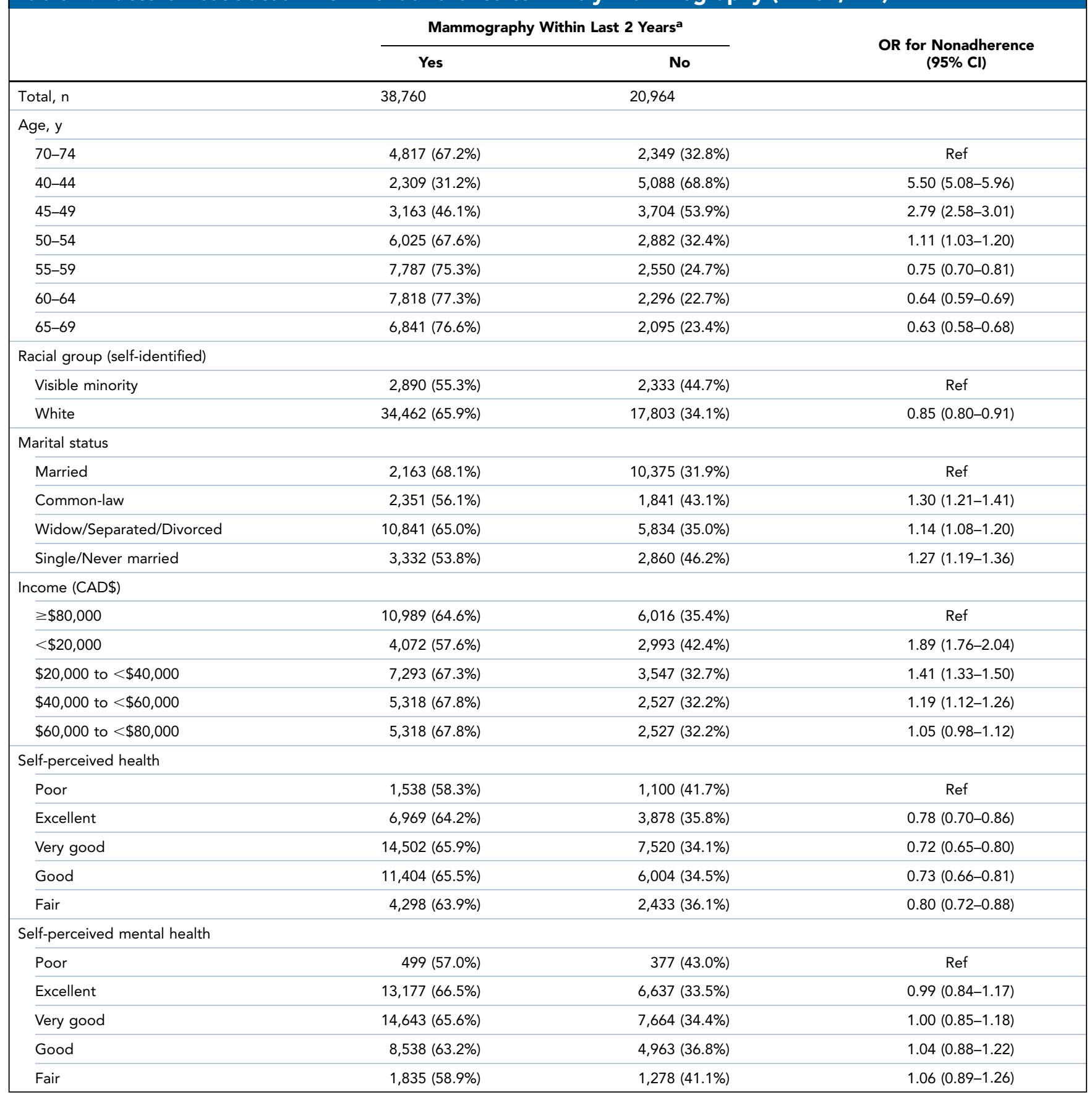

Abbreviation: OR, odds ratio.

a Missing data: self-identified racial group $(n=2,236 ; 3.7 \%)$, marital status $(n=127 ; 0.2 \%)$, income $(n=4,045 ; 6.8 \%)$, self-perceived health $(n=78 ; 0.1 \%)$, self-perceived mental health $(n=113 ; 0.2 \%)$.

\section{Results}

CRC Screening Cohort

A total of 99,820 participants were considered eligible for the CRC screening cohort and included in the analysis. This included 56,470 participants who had FOBT within the last 2 years and/or colonoscopy/sigmoidoscopy within the last 10 years and 43,350 who did not have any of these procedures. Patients who did not undergo these investigations were more likely to be younger (aged 50-54 years), male, unmarried, and a self-identified visible minority; have better self-perceived health; and have lower income $(<\$ 20,000 \mathrm{CAD})$ 
Table 3. Factors Associated With Nonadherence to Timely Papanicolaou Test $(N=46,767)$

$\begin{array}{ccc}\text { Papanicolaou Test Within Last } 3 \text { Years }^{\text {a }} & \text { OR for Nonadherence } \\ \text { (95\% Cl) }\end{array}$

\begin{tabular}{|c|c|c|c|}
\hline Total, N & 34,957 & 11,810 & \\
\hline \multicolumn{4}{|l|}{ Age, y } \\
\hline $65-69$ & $3,092(56.8 \%)$ & $2,354(43.2 \%)$ & Ref \\
\hline $30-34$ & 4,155 (86.8\%) & $633(13.2 \%)$ & $0.20(0.17-0.22)$ \\
\hline $35-39$ & $4,197(85.8 \%)$ & $696(14.2 \%)$ & $0.22(0.20-0.25)$ \\
\hline $50-54$ & $4,028(72.7 \%)$ & $1,510(27.3 \%)$ & $0.52(0.47-0.56)$ \\
\hline $55-59$ & $4,398(69.8 \%)$ & 1,905 (30.2\%) & $0.61(0.56-0.66)$ \\
\hline $60-64$ & $4,043(64.3 \%)$ & 2,245 (35.7\%) & $0.74(0.68-0.90)$ \\
\hline \multicolumn{4}{|l|}{ Racial group (self-identified) } \\
\hline Married & $20,190(77.1 \%)$ & $5,986(22.9 \%)$ & Ref \\
\hline Common-law & $3,054(80.6 \%)$ & $733(19.4 \%)$ & $1.01(0.91-1.11)$ \\
\hline Widow/Separated/Divorced & $6,358(67.7 \%)$ & $3,038(32.3 \%)$ & $0.97(0.91-1.03)$ \\
\hline Single/Never married & $5,266(72.3 \%)$ & $2,014(27.7 \%)$ & $1.46(1.36-1.56)$ \\
\hline \multicolumn{4}{|l|}{ Income (CAD\$) } \\
\hline$\geq \$ 80,000$ & $13,124(83.0 \%)$ & $2,688(17.0 \%)$ & Ref \\
\hline$<\$ 20,000$ & $2,764(60.8 \%)$ & $1,780(39.2 \%)$ & $1.96(1.79-2.14)$ \\
\hline$\$ 20,000$ to $<\$ 40,000$ & $5,704(67.7 \%)$ & $2,720(32.3 \%)$ & $1.56(1.45-1.67)$ \\
\hline$\$ 40,000$ to $<\$ 60,000$ & $5,893(72.7 \%)$ & $2,213(27.3 \%)$ & $1.41(1.31-1.51)$ \\
\hline Fair & $2,741(63.4 \%)$ & $1,583(36.6 \%)$ & $0.83(0.73-0.95)$ \\
\hline \multicolumn{4}{|l|}{ Self-perceived mental health } \\
\hline Poor & $454(62.2 \%)$ & $276(37.8 \%)$ & Ref \\
\hline Excellent & $12,141(76.8 \%)$ & $3,660(23.2 \%)$ & $0.85(0.71-1.02)$ \\
\hline Very good & $13,397(76 \%)$ & $4,235(24 \%)$ & $0.86(0.72-1.03)$ \\
\hline Good & $7,193(71.9 \%)$ & $2,811(28.1 \%)$ & $0.87(0.72-1.04)$ \\
\hline Fair & $1,730(68.7 \%)$ & 788 (31.3\%) & $0.85(0.70-1.03)$ \\
\hline
\end{tabular}

Abbreviation: OR, odds ratio.

aMissing data: self-identified racial group $(n=2,259 ; 5 \%)$, marital status $(n=128 ; 0.3 \%)$, income $(n=3,064 ; 6.6 \%)$, self-perceived health $(n=53 ; 0.1 \%)$, self-perceived mental health $(n=82 ; 0.1 \%)$.

$(P<.001$ for all) (Table 1). Weighted frequencies for this analysis are reported in supplemental eTable 2.

Within multivariable logistic regression analysis, the following factors were associated with not having timely
CRC screening tests: age 50 to 54 years (odds ratio [OR], 2.65; 95\% CI, 2.53-2.79), male sex (OR, 1.21; 95\% CI, $1.18-1.24$ ), self-identified visible minority (OR for White race vs visible minority, 0.87 ; $95 \%$ CI, 0.83-0.92), 
single/never married status (OR, 1.28; 95\% CI, 1.22-1.35), income $<\$ 20,000 \mathrm{CAD}$ (OR, 1.86; 95\% CI, 1.76-1.97), and better self-perceived health (OR, 1.64; 95\% CI, 1.51-1.77) (Table 1). When repeating the analysis excluding patients who reported a concurrent cancer diagnosis, the same results were obtained (data not shown).

\section{Breast Cancer Screening Cohort}

A total of 59,724 participants were considered eligible for the breast cancer screening cohort (using the age group of 40-74 years) and were included in the analysis. This included 38,760 participants who underwent mammography within the last 2 years and 20,964 who did not. Patients who did not have timely mammography were more likely to be unmarried, a self-identified visible minority, and aged 40 to 54 years; have worse self-perceived health; and have lower income $(<\$ 20,000 \mathrm{CAD})(P<.001$ for all) (Table 2). Weighted frequencies for this analysis are reported in supplemental eTable 3.

Within multivariable logistic regression analysis, the following factors were associated with not having timely mammography: age 40 to 44 years (OR, 5.50; 95\% CI, 5.08-5.96), self-identified visible minority (OR for selfidentified White race vs self-identified visible minority, 0.85; 95\% CI, 0.80-0.91), single/never married status (OR, 1.27 ; 95\% CI, 1.19-1.36), income $<\$ 20,000$ CAD (OR, 1.89; 95\% CI, 1.76-2.04), and poor self-perceived health (OR for excellent vs poor self-perceived health, 0.78 ; $95 \% \mathrm{CI}$, 0.70-0.86) (Table 2). When repeating the same analysis excluding either patients aged $<50$ years or those who reported a concurrent cancer diagnosis, the same results were obtained in both scenarios (data not shown).

\section{Cervical Cancer Screening Cohort}

A total of 46,767 participants were considered eligible for the cervical cancer screening cohort and were included in the analysis. This included 34,957 participants who had the Pap test performed within the last 3 years and 11,810 who did not. Patients who did not have a timely Pap test were more likely to be older (aged 65-69 years), unmarried, and a self-identified visible minority; have worse self-perceived health; and have lower income
$(<\$ 20,000 \mathrm{CAD})(P<.001$ for all) (Table 3$)$. Weighted frequencies for this analysis are reported in supplemental eTable 4.

Within multivariable logistic regression analysis, the following factors were associated with not having a timely Pap test: age 65 to 69 years (OR for age 25-29 vs 65-69 years, 0.20 ; $95 \%$ CI, 0.18-0.23), self-identified visible minority (OR for self-identified White race vs selfidentified visible minority, 0.66 ; $95 \% \mathrm{CI}, 0.61-0.70$ ), income $<\$ 20,000 \mathrm{CAD}$ (OR, 1.96; 95\% CI, 1.79-2.14), and poor self-perceived health (OR for excellent vs poor selfperceived health, $0.53 ; 95 \%$ CI, 0.46-0.61) (Table 3). When repeating the same analysis excluding patients who reported a concurrent cancer diagnosis, the same results were obtained (data not shown).

\section{Temporal and Geographic Variations in Screening}

Yearly rates of guideline-concordant screening tests among different cohorts are summarized in Figure 1. For the 3 screening cohorts, rates of screening increased modestly throughout the study period (2007-2016). Additional assessment of the variability of screening test adherence among different Canadian jurisdictions is provided in Figure $2 \mathrm{~A}-\mathrm{C}$, and additional analysis of temporal and geographic variations in screening after adjusting for sample weights is provided in supplemental eFigures 1 and 2.

\section{Discussion}

This study provides an assessment of the patterns and trends of the 3 CTFPHC-recommended cancer screening approaches in a contemporary Canadian cohort. It suggests that more than one-third of eligible individuals are missing timely screening tests for CRC. Moreover, at least one-quarter of eligible women are missing their recommended breast and cervical cancer screening tests.

This investigation showed evidence of social and economic disparities regarding adherence to cancer screening recommendations; for instance, individuals with lower income were more likely to miss their recommended screening tests. These findings complement previously published literature that highlighted the

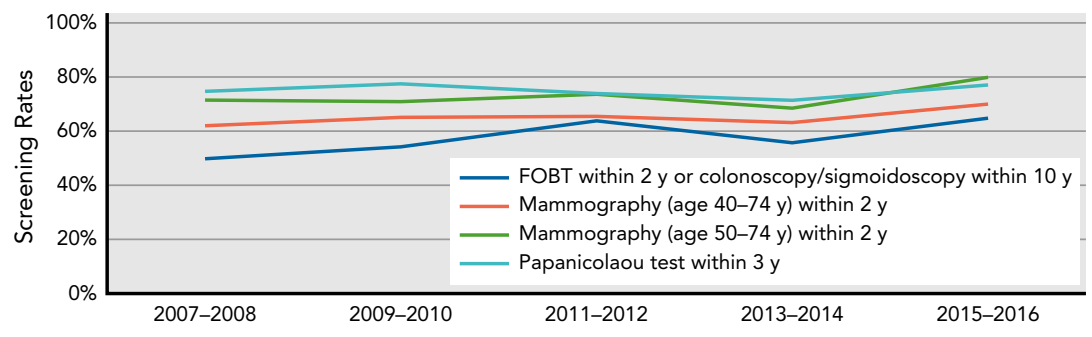

Figure 1. Yearly rates of guideline-concordant screening tests among different cohorts. Abbreviation: FOBT, fecal occult blood test. 
A

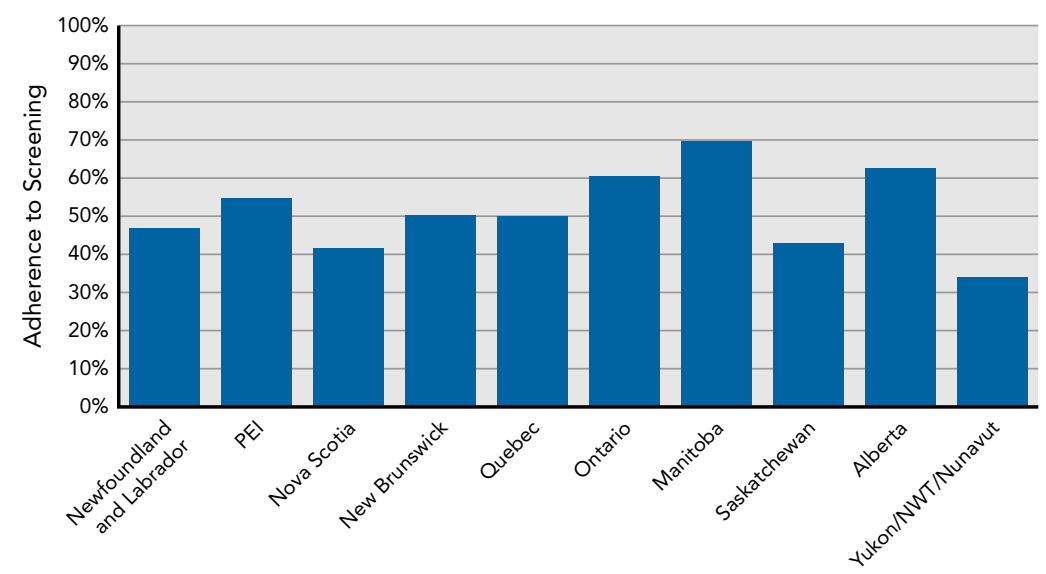

B

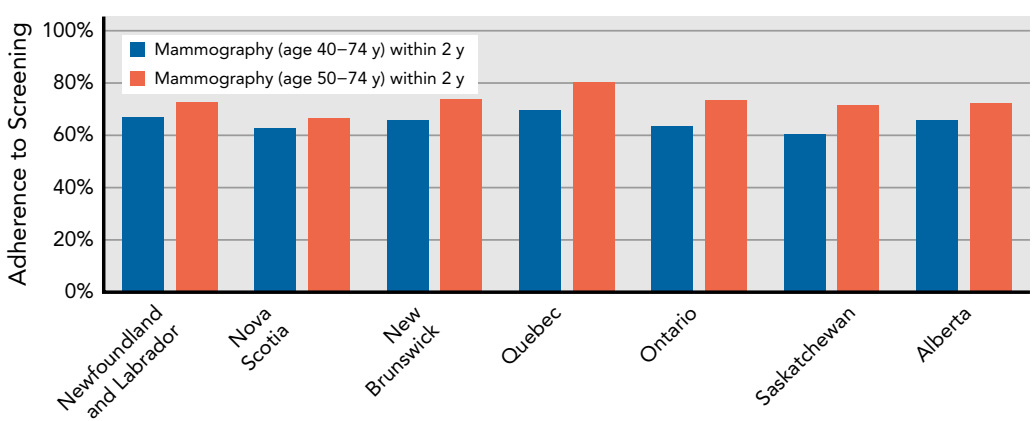

C

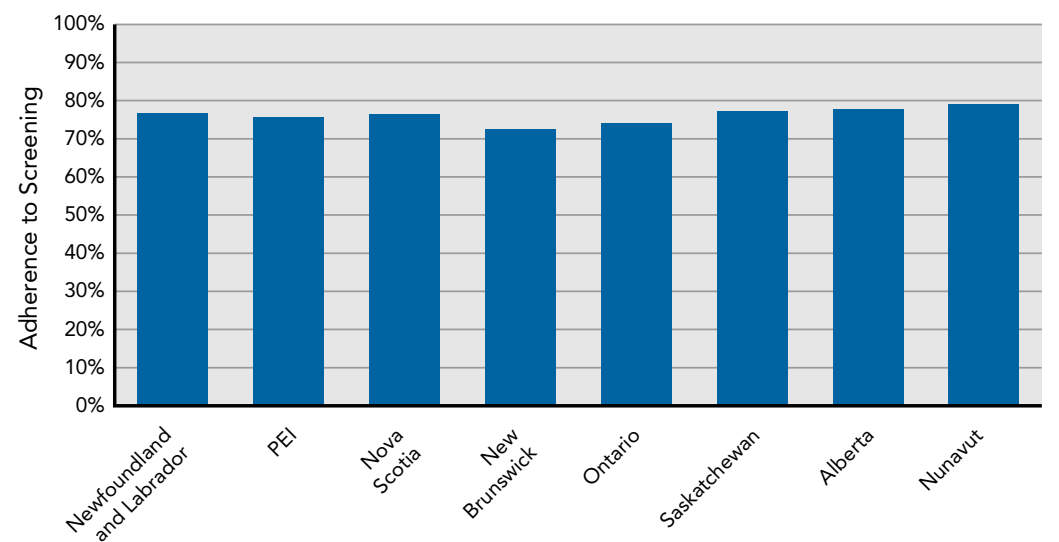

Figure 2. Variability of screening test adherence among different Canadian jurisdictions for (A) colorectal cancer screening (fecal occult blood test within 2 years or colonoscopy/sigmoidoscopy within 10 years), (B) breast cancer screening, and (C) cervical cancer screening (Papanicolaou test within 3 years).

Abbreviations: NWT, Northwest Territories; PEI, Prince Edward Island.

deleterious impact of low socioeconomic status on the outcomes of various cancers in North America. ${ }^{16-18}$ Likewise, the current study suggests that people who self-identify as a visible minority are less likely to have timely screening tests. This is consistent with older studies suggesting a lower uptake of cancer screening among self-identified visible minorities in North America and highlights the need to address this disparity. ${ }^{19,20}$

This study has several limitations that must be acknowledged. First, the CCHS surveys are based on self-reporting by participants. The reliance on self-reporting may be associated with different sorts of bias within the 
results of this analysis. Previous US population-based studies have suggested that there may be overreporting of cancer screening within national US surveys. ${ }^{21,22}$ Second, some of the screening tests reported in the CCHS datasets may not have been conducted for the sake of screening but rather in the course of investigating a specific symptom. To minimize the impact of this limitation, a sensitivity analysis was performed to exclude participants with a concurrent cancer diagnosis. Third, given the cross-sectional nature of CCHS data collection and the absence of subsequent longitudinal morbidity and mortality follow-up, it is not possible to link nonadherence to screening tests with rates of subsequent cancer diagnosis and/or cancer mortality. Fourth, the linkage process described in the CCHS methodology between responses recorded from participants together with other surveys (that could have been conducted through other federal entities and/or provincial bodies) may have led to different forms of bias in collecting and interpreting the data of the current analysis. In addition, and as described in the methodology of CCHS, there was a redesign of the sampling strategy between the 2015-2016 CCHS datasets and prior published CCHS datasets; thus, Statistics Canada has suggested caution when comparing data from older cycles to data released for the 2015 cycle onward. ${ }^{9}$ Finally, restricting the estimates to patients who do not have cancer likely does little to adjust for testing that is diagnostic instead of testing that is performed for screening purposes because cancer detection will only represent a very small fraction of the proportion of adults who are evaluated for symptoms; in addition, a woman with breast cancer may still be referred to cervical cancer screening and CRC screening. These limitations need to be weighed against the clear strengths of the current analysis, including a large sample size and known quality of the CCHS data collection process.

The findings of the current study should serve as a wake-up call to healthcare providers and policymakers in Canada. Proper attention to the treatment of patients with cancer is needed; at the same time, more focus on recommended screening strategies would most likely lead to lower cancer mortality and a significant cost savings to publicly funded healthcare (through a reduction in the number of individuals presenting with advanced cancer who would need more expensive treatments). A specific focus should be on marginalized racial and socioeconomic demographic groups in Canada who seem to have a higher probability of missing their recommended timely screening investigations. Some strategies have been previously recommended to increase uptake of cancer screening, including convincing physicians of the importance of cancer screening (physician recommendation is the most important factor in adherence to cancer screening ${ }^{23}$ ) and educating the public about the importance of regular cancer screening. Electronic medical record-based reminders (targeting physicians, patients, or both) are also effective to ensure adherence to cancer screening. ${ }^{24,25}$ That being said, some practical issues with differing electronic medical records between different providers may impair this functionality. All primary care practitioners should also have an office policy regarding recommended cancer screening tests. ${ }^{26}$

Although the suggestions for improving screening rates are useful, it is also important to consider the impact of cultural factors/barriers to screening that exist, particularly for cancers specific to women. ${ }^{27}$ Studies have suggested that culturally competent outreach to particular immigrant communities is important, particularly in a country that welcomes many immigrants every year such as Canada. ${ }^{28,29}$

\section{Conclusions}

More than one-third of eligible individuals are missing timely screening tests for CRC, and at least one-quarter of eligible women are missing their recommended breast and cervical cancer screening tests. Therefore, greater efforts must be made by federal and provincial health authorities to deal with socioeconomic disparities in access to cancer screening.

Submitted February 14, 2020; accepted for publication June 26, 2020.

Disclosures: Dr. Abdel-Rahman has disclosed that he is on the advisory board for Eisai Canada.

Correspondence: Omar Abdel-Rahman, MD, Department of Oncology, University of Alberta and Cross Cancer Institute, 11560 University Avenue, Edmonton, Alberta, Canada T4G 1Z2. Email: omar.abdelsalam@ahs.ca

\section{References}

1. Lofters AK, Mark A, Taljaard M, et al. Cancer screening inequities in a time of primary care reform: a population-based longitudinal study in Ontario, Canada. BMC Fam Pract 2018;19:147.

2. Miller EA, Pinsky PF, Schoen RE, et al. Effect of flexible sigmoidoscopy screening on colorectal cancer incidence and mortality: long-term follow-up of the randomised US PLCO cancer screening trial. Lancet Gastroenterol Hepatol 2019;4:101-110.

3. Weedon-Fekjær H, Romundstad PR, Vatten LJ. Modern mammography screening and breast cancer mortality: population study. BMJ 2014;348: g3701.

4. Bibbins-Domingo K, Grossman DC, Curry SJ, et al. Screening for colorectal cancer: US Preventive Services Task Force recommendation statement. JAMA 2016;315:2564-2575.

5. Klarenbach S, Sims-Jones N, Lewin G, et al. Recommendations on screening for breast cancer in women aged $40-74$ years who are not at increased risk for breast cancer. CMAJ 2018;190: E1441-1451.

6. Peirson L, Fitzpatrick-Lewis D, Ciliska D, et al. Screening for cervical cancer: a systematic review and meta-analysis. Syst Rev 2013; $2: 35$. 
7. Clarke TC, Soler-Vila H, Fleming LE, et al. Trends in adherence to recommended cancer screening: the US population and working cancer survivors. Front Oncol 2012;2:190.

8. Government of Canada. Canadian Community Health Survey. Accessed July 4, 2020. Available at: https://www.canada.ca/en/health-canada/ services/food-nutrition/food-nutrition-surveillance/health-nutritionsurveys/canadian-community-health-survey-cchs.html

9. Statistics Canada. Canadian Community Health Survey-annual component (CCHS). Accessed July 4, 2020. Available at: https:// www23.statcan.gc.ca/imdb/p2SV.pl?Function=getSurvey\&SDDS $=3226$

10. Statistics Canada. Canadian Community Health Survey-annual component (CCHS), list of surveys in collection. Accessed July 4, 2020 Available at: https://www.statcan.gc.ca/eng/survey/household/3226

11. Canadian Task Force on Preventive Health Care. Published guidelines. Accessed July 4, 2020. Available at: https://canadiantaskforce.ca/ guidelines/published-guidelines/

12. Canadian Task Force on Preventive Health Care. Recommendations on screening for colorectal cancer in primary care. CMAJ 2016;188: 340-348.

13. Dickinson J, Tsakonas E, Conner Gorber $\mathrm{S}$, et al. Recommendations on screening for cervical cancer. CMAJ 2013;185:35-45.

14. Bell N, Conner Gorber S, Shane A, et al. Recommendations on screening for prostate cancer with the prostate-specific antigen test. CMAJ 2014; 186:1225-1234

15. Thomas S, Wannell B. Combining cycles of the Canadian Community Health Survey. Health Rep 2009;20:53-58.

16. Abdel-Rahman $\mathrm{O}$. Impact of $\mathrm{NCl}$ Socioeconomic Index on the outcomes of nonmetastatic breast cancer patients: analysis of SEER census tract-level socioeconomic database. Clin Breast Cancer 2019; 19:e717-722.

17. Abdel-Rahman O. Prognostic impact of socioeconomic status among patients with malignant melanoma of the skin: a population-based study. J Dermatolog Treat 2020;31:571-575.

18. Abdel-Rahman O. Treatment choices and outcomes of non-metastatic hepatocellular carcinoma patients in relationship to neighborhood socioeconomic status: a population-based study. Int J Clin Oncol 2020;25 861-866.

19. Amankwah $\mathrm{E}$, Ngwakongnwi $\mathrm{E}$, Quan $\mathrm{H}$. Why many visible minority women in Canada do not participate in cervical cancer screening. Ethn Health 2009;14:337-349.

20. Ji CS, Chen MY, Sun J, et al. Cultural views, English proficiency and regular cervical cancer screening among older Chinese American women. Womens Health Issues 2010;20:272-278.

21. Cronin KA, Miglioretti DL, Krapcho $M$, et al. Bias associated with self-report of prior screening mammography. Cancer Epidemiol Biomarkers Prev 2009;18:1699-1705.

22. Vernon SW, Abotchie PN, McQueen A, et al. Is the accuracy of self-reported colorectal cancer screening associated with social desirability? Cancer Epidemiol Biomarkers Prev 2012;21:61-65.

23. Sarfaty M, Wender R. How to increase colorectal cancer screening rates in practice. CA Cancer J Clin 2007;57:354-366.

24. Klabunde CN, Frame PS, Meadow A, et al. A national survey of primary care physicians' colorectal cancer screening recommendations and practices. Prev Med 2003;36:352-362.

25. Whitlock EP, Lin JS, Liles E, et al. Screening for colorectal cancer: a targeted, updated systematic review for the U.S. Preventive Services Task Force. Ann Intern Med 2008;149:638-658.

26. Rex DK, Johnson DA, Anderson JC, et al. American College of Gastroenterology guidelines for colorectal cancer screening 2009 [corrected]. Am J Gastroenterol 2009;104:739-750.

27. Kue J, Hanegan H, Tan A. Perceptions of cervical cancer screening screening behavior, and post-migration living difficulties among Bhutanese-Nepali refugee women in the United States. J Community Health 2017;42:1079-1089.

28. Gondek M, Shogan M, Saad-Harfouche FG, et al. Engaging immigrant and refugee women in breast health education. J Cancer Educ 2015;30: 593-598.

29. Raines Milenkov A, Felini M, Baker E, et al. Uptake of cancer screenings among a multiethnic refugee population in North Texas, 2014-2018. PLoS One 2020;15:e0230675.

\section{See JNCCN.org for supplemental online content.}


Supplemental online content for:

\section{Patterns and Trends of Cancer Screening in Canada: Results From a Contemporary National Survey}

Omar Abdel-Rahman, MD

J Natl Compr Canc Netw 2021;19(1):68-76

eFigure 1: Yearly Rates of Guideline-Concordant Screening Tests Among Different Cohorts eFigure 2: Variability of Screening Test Adherence Among Different Canadian Jurisdictions eTable 1: Availability of Screening Information Among Canadian Jurisdictions eTable 2: Weighted Frequencies for Factors Associated With Nonadherence to CRC Screening eTable 3: Weighted Frequencies for Factors Associated With Nonadherence to Timely Mammography eTable 4: Weighted Frequencies for Factors Associated With Nonadherence to Timely Papanicolaou Test 


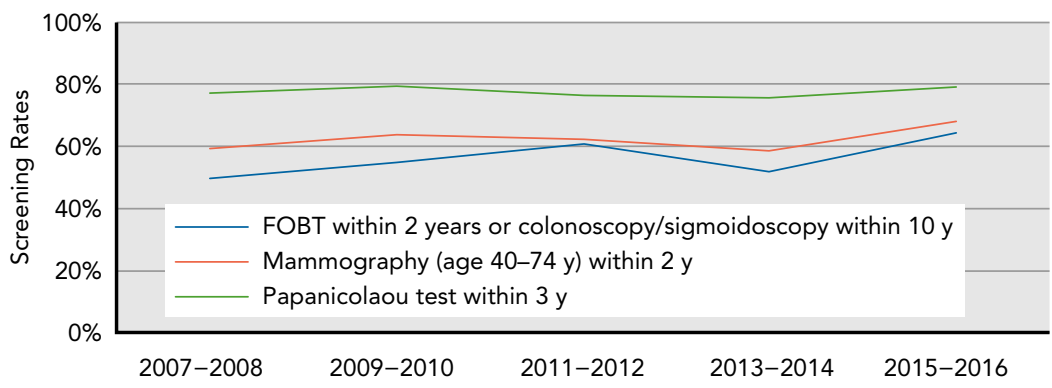

eFigure 1. Yearly rates of guideline-concordant screening tests among different cohorts, adjusted for sample weights of Canadian Community Health Survey.

Abbreviation: FOBT, fecal occult blood test. 
A

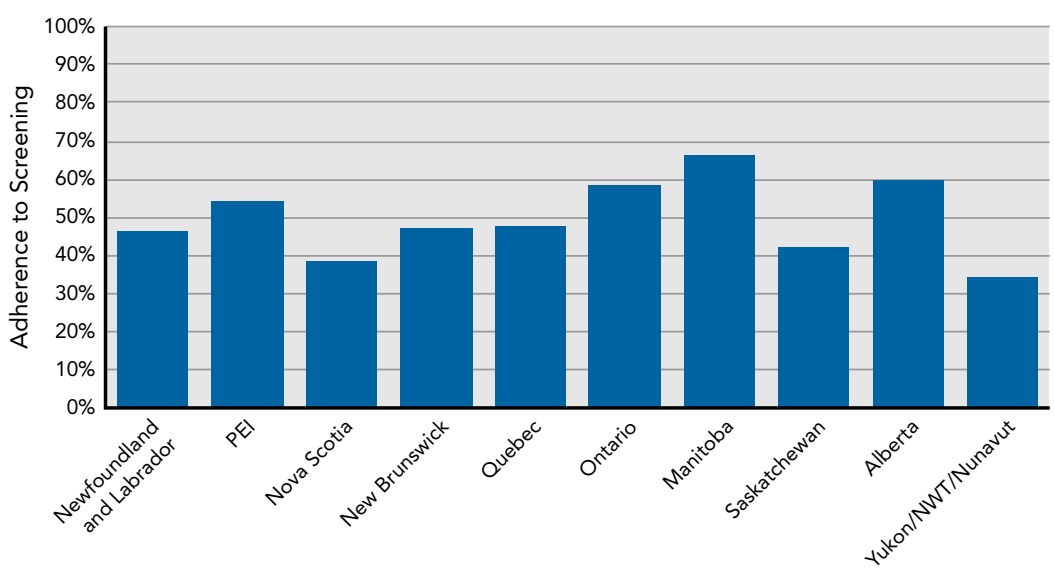

B

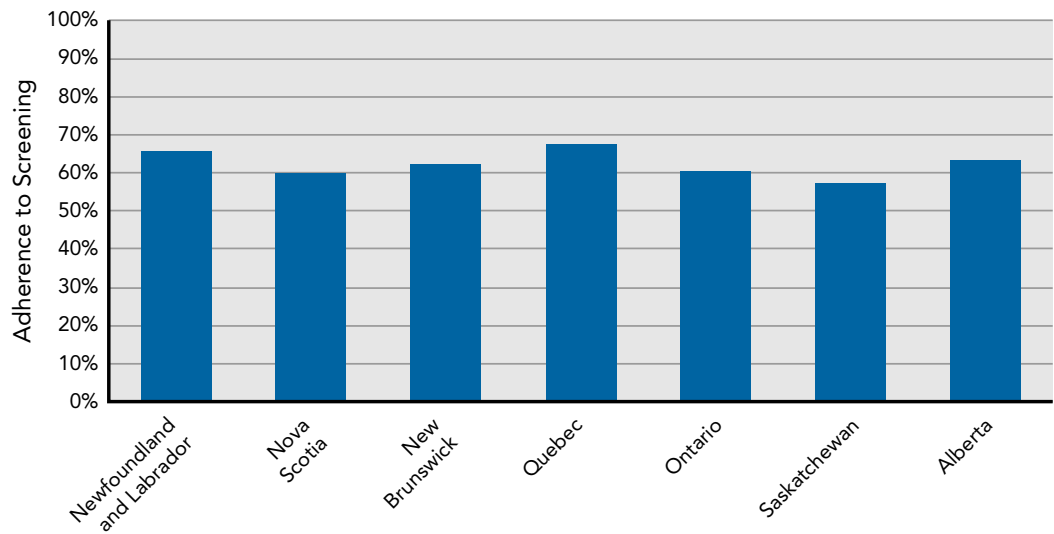

C

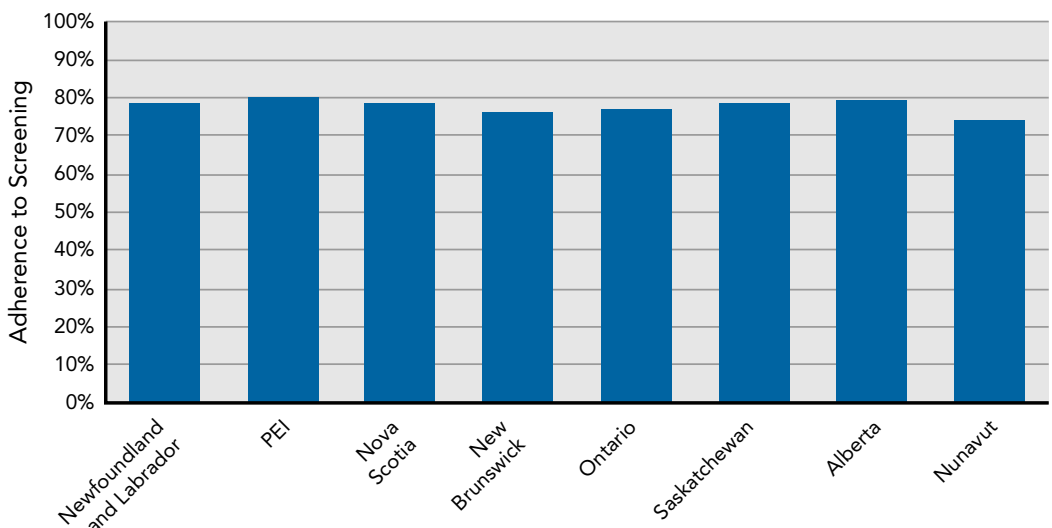

eFigure 2. Variability of screening test adherence among different Canadian jurisdictions, adjusted for sample weights of Canadian Community Health Survey. (A) Colorectal cancer screening: fecal occult blood test within 2 years or colonoscopy/sigmoidoscopy within 10 years. (B) Breast cancer screening: mammography (age 40-74 years) within 2 years. (C) Cervical cancer screening: Papanicolaou test within 3 years.

Abbreviations: NWT, Northwest Territories; PEI, Prince Edward Island. 


\section{eTable 1. Availability of Screening Information Among Canadian Jurisdictions Within CCHS Datasets}

\begin{tabular}{|c|c|c|c|}
\hline Province & FOBT \pm Sigmoidoscopy/Colonoscopy & Mammography & Papanicolaou Test \\
\hline Newfoundland \& Labrador & Available & Available & Available \\
\hline PEI & Available & Not available & Available \\
\hline Nova Scotia & Available & Available & Available \\
\hline New Brunswick & Available & Available & Available \\
\hline Quebec & Available & Available & Not available \\
\hline Ontario & Available & Available & Available \\
\hline Manitoba & Available & Not available & Not available \\
\hline Saskatchewan & Available & Available & Available \\
\hline Alberta & Available & Available & Available \\
\hline British Columbia & Not available & Not available & Not available \\
\hline Yukon/NWT/Nunavut & Available & Not available & Available ${ }^{a}$ \\
\hline
\end{tabular}

Abbreviations: CCHS, Canadian Community Health Survey; CRC, colorectal cancer; FOBT, fecal occult blood test; NWT, Northwest Territories; PEI, Prince Edward Island.

aNunavut only (note that these 3 jurisdictions were reported collectively in all CCHS datasets except in the 2015-2016 dataset, where they were separated). 


\begin{tabular}{|c|c|c|}
\hline \multicolumn{3}{|c|}{$\begin{array}{l}\text { eTable 2. Weighted Frequencies for Factors } \\
\text { Associated With Nonadherence to } \\
\text { CRC Screening }{ }^{a}\end{array}$} \\
\hline & \multicolumn{2}{|c|}{$\begin{array}{l}\text { FOBT Within Last } \\
2 \text { Years and/or } \\
\text { Sigmoidoscopy/ } \\
\text { Colonoscopy Within } \\
\text { Last } 10 \text { Years }\end{array}$} \\
\hline & Yes & No \\
\hline Total & $55.4 \%$ & $44.6 \%$ \\
\hline \multicolumn{3}{|l|}{ Age } \\
\hline $50-54$ y & $43.5 \%$ & $56.5 \%$ \\
\hline $55-59$ y & $54.7 \%$ & $45.3 \%$ \\
\hline $60-64$ y & $60.8 \%$ & $39.2 \%$ \\
\hline $65-69 y$ & $63.1 \%$ & $36.9 \%$ \\
\hline $70-74$ y & $64.1 \%$ & $35.9 \%$ \\
\hline \multicolumn{3}{|l|}{ Sex } \\
\hline Male & $54.2 \%$ & $45.8 \%$ \\
\hline Female & $56.6 \%$ & $43.4 \%$ \\
\hline \multicolumn{3}{|l|}{ Racial group (self-identified) } \\
\hline White & $56.9 \%$ & $43.1 \%$ \\
\hline Visible minority & $47.3 \%$ & $52.7 \%$ \\
\hline \multicolumn{3}{|l|}{ Marital status } \\
\hline Married & $57.6 \%$ & $42.4 \%$ \\
\hline Common-law & $50.8 \%$ & $49.2 \%$ \\
\hline Widow/Separated/Divorced & $52.4 \%$ & $47.6 \%$ \\
\hline Single/Never married & $47.0 \%$ & $53.0 \%$ \\
\hline \multicolumn{3}{|l|}{ Income (CAD\$) } \\
\hline$<\$ 20,000$ & $47.3 \%$ & $52.7 \%$ \\
\hline$\$ 20,000$ to $<\$ 40,000$ & $52.8 \%$ & $47.2 \%$ \\
\hline$\$ 40,000$ to $<\$ 60,000$ & $55.8 \%$ & $44.2 \%$ \\
\hline$\$ 60,000$ to $<\$ 80,000$ & $55.2 \%$ & $44.8 \%$ \\
\hline$>\$ 80,000$ & $58.9 \%$ & $41.1 \%$ \\
\hline \multicolumn{3}{|l|}{ Self-perceived health } \\
\hline Excellent & $54.4 \%$ & $45.6 \%$ \\
\hline Very good & $55.7 \%$ & $44.3 \%$ \\
\hline Good & $54.9 \%$ & $45.1 \%$ \\
\hline Fair & $56.6 \%$ & $43.4 \%$ \\
\hline Poor & $58.6 \%$ & $41.4 \%$ \\
\hline \multicolumn{3}{|l|}{ Self-perceived mental health } \\
\hline Excellent & $5.6 \%$ & $44.4 \%$ \\
\hline Very good & $56.1 \%$ & $43.9 \%$ \\
\hline Good & $54.2 \%$ & $45.8 \%$ \\
\hline Fair & $54.9 \%$ & $45.1 \%$ \\
\hline Poor & $54.7 \%$ & $45.3 \%$ \\
\hline
\end{tabular}

aMissing data: racial group (3.9\%), marital status $(0.2 \%)$, income $(7.1 \%)$, self-perceived health $(0.2 \%)$, self-perceived mental health $(0.2 \%)$.

\section{eTable 3. Weighted Frequencies for Factors Associated With Nonadherence to Timely Mammography}

\begin{tabular}{|lcc} 
& \multicolumn{2}{c}{$\begin{array}{c}\text { Mammography Within } \\
\text { Last 2 Years }\end{array}$} \\
\cline { 2 - 3 } & Yes & No \\
\hline Total & $62.6 \%$ & $37.4 \%$ \\
\hline Age & & \\
\hline $40-44$ y & $33.7 \%$ & $66.3 \%$ \\
\hline $45-49$ y & $48.5 \%$ & $51.5 \%$ \\
\hline $50-54$ y & $69.0 \%$ & $31.0 \%$ \\
\hline $55-59$ y & $75.4 \%$ & $24.6 \%$ \\
\hline $60-64$ y & $78.4 \%$ & $21.6 \%$ \\
\hline $70-69$ y & $76.6 \%$ & $23.4 \%$ \\
\hline ya & $67.9 \%$ & $32.1 \%$ \\
\hline
\end{tabular}

Racial group (self-identified)

\begin{tabular}{|c|c|c|}
\hline White & $63.9 \%$ & $36.1 \%$ \\
\hline Visible minority & $56.2 \%$ & $43.8 \%$ \\
\hline \multicolumn{3}{|l|}{ Marital status } \\
\hline Married & $64.8 \%$ & $35.2 \%$ \\
\hline Common-law & $56.4 \%$ & $43.6 \%$ \\
\hline Widow/Separated/Divorced & $62.3 \%$ & $37.7 \%$ \\
\hline Single/Never married & $53.0 \%$ & $47.0 \%$ \\
\hline
\end{tabular}

Income (CAD\$)

\begin{tabular}{lll}
\hline$<\$ 20,000$ & $54.8 \%$ & $45.2 \%$ \\
\hline$\$ 20,000$ to $<\$ 40,000$ & $61.2 \%$ & $38.8 \%$ \\
\hline$\$ 40,000$ to $<\$ 60,000$ & $64.2 \%$ & $35.8 \%$ \\
\hline$\$ 60,000$ to $<\$ 80,000$ & $63.8 \%$ & $36.2 \%$ \\
\hline$>\$ 80,000$ & $63.5 \%$ & $36.5 \%$
\end{tabular}

Self-perceived health

\begin{tabular}{lll}
\hline Excellent & $63.3 \%$ & $36.7 \%$ \\
\hline Very good & $62.9 \%$ & $37.1 \%$ \\
\hline Good & $62.5 \%$ & $37.5 \%$ \\
\hline Fair & $62.1 \%$ & $37.9 \%$ \\
\hline Poor & $56.8 \%$ & $43.2 \%$
\end{tabular}

Self-perceived mental health

\begin{tabular}{lll}
\hline Excellent & $64.8 \%$ & $35.2 \%$ \\
\hline Very good & $62.3 \%$ & $37.7 \%$ \\
\hline Good & $61.3 \%$ & $38.7 \%$ \\
\hline Fair & $57.0 \%$ & $43.0 \%$ \\
\hline Poor & $54.9 \%$ & $45.1 \%$ \\
\hline
\end{tabular}

aMissing data: racial group (3.9\%), marital status $(0.2 \%)$, income $(7.1 \%)$, self-perceived health $(0.2 \%)$, self-perceived mental health $(0.2 \%)$. 


\begin{tabular}{|c|c|c|}
\hline \multicolumn{3}{|c|}{$\begin{array}{l}\text { eTable 4. Weighted Frequencies for Factors } \\
\text { Associated With Nonadherence to } \\
\text { Timely Papanicolaou Test }\end{array}$} \\
\hline & \multicolumn{2}{|c|}{$\begin{array}{l}\text { Papanicolaou Test } \\
\text { Within Last } 3 \text { Years }\end{array}$} \\
\hline & Yes & No \\
\hline Total & $77.3 \%$ & $22.7 \%$ \\
\hline \multicolumn{3}{|l|}{ Age } \\
\hline $25-29$ y & $82.0 \%$ & $18.0 \%$ \\
\hline $30-34$ y & $85.6 \%$ & $14.4 \%$ \\
\hline $35-39$ y & $83.6 \%$ & $16.4 \%$ \\
\hline $40-44$ y & $83.0 \%$ & $17.0 \%$ \\
\hline $45-49$ y & $80.5 \%$ & $19.5 \%$ \\
\hline $50-54$ y & $75.8 \%$ & $24.2 \%$ \\
\hline $55-59$ y & $71.9 \%$ & $28.1 \%$ \\
\hline $60-64$ y & $66.8 \%$ & $33.2 \%$ \\
\hline $65-69$ y & $57.3 \%$ & $42.7 \%$ \\
\hline \multicolumn{3}{|l|}{ Racial group (self-identified) } \\
\hline White & $79.3 \%$ & $20.7 \%$ \\
\hline Visible minority & $71.5 \%$ & $28.5 \%$ \\
\hline \multicolumn{3}{|l|}{ Marital status } \\
\hline Married & $78.7 \%$ & $21.3 \%$ \\
\hline Common-law & $82.3 \%$ & $17.7 \%$ \\
\hline Widow/Separated/Divorced & $72.7 \%$ & $27.3 \%$ \\
\hline Single/Never married & $73.3 \%$ & $26.7 \%$ \\
\hline \multicolumn{3}{|l|}{ Income (CAD\$) } \\
\hline$<\$ 20,000$ & $65.1 \%$ & $34.9 \%$ \\
\hline$\$ 20,000$ to $<\$ 40,000$ & $69.7 \%$ & $30.3 \%$ \\
\hline$\$ 40,000$ to $<\$ 60,000$ & $74.8 \%$ & $25.2 \%$ \\
\hline$\$ 60,000$ to $<\$ 80,000$ & $79.1 \%$ & $20.9 \%$ \\
\hline$>\$ 80,000$ & $83.3 \%$ & $16.7 \%$ \\
\hline \multicolumn{3}{|l|}{ Self-perceived health } \\
\hline Excellent & $82.2 \%$ & $17.8 \%$ \\
\hline Very good & $80.4 \%$ & $19.6 \%$ \\
\hline Good & $73.9 \%$ & $26.1 \%$ \\
\hline Fair & $66.5 \%$ & $33.5 \%$ \\
\hline Poor & $61.8 \%$ & $38.2 \%$ \\
\hline \multicolumn{3}{|l|}{ Self-perceived mental health } \\
\hline Excellent & $78.8 \%$ & $21.2 \%$ \\
\hline Very good & $78.5 \%$ & $21.5 \%$ \\
\hline Good & $75.7 \%$ & $24.3 \%$ \\
\hline Fair & $70.3 \%$ & $29.7 \%$ \\
\hline Poor & $61.6 \%$ & $38.4 \%$ \\
\hline
\end{tabular}

aMissing data: racial group (4.4\%), marital status (0.2\%), income (6.1\%), self-perceived health $(0.1 \%)$, self-perceived mental health $(0.1 \%)$. 